\title{
IN THE NEWS/
}

\section{FDA USER FEES GAIN MOMENTUM}

-The U.S. Food and Drug Administration (FDA, Bethesda, MD) and the drug industry are near an agreement regarding user fees to speed up the drug approval process. Under the plan, FDA proposes that drug companies pay several fees: $\$ 150,000$ for each drug application, regardless of whether it is in a life-saving category ; $\$ 50,000$ per company per year; $\$ 5,000$ for each product on the market. Generic drugs and medical devices would not yet be included in the plan. In return for the fees, FDA must cut the average time it takes to review new drug applications from the more than 20 months currently to 12 months, and cut the average time of review on life-saving drugs to six months from the current one year. To accomplish this, the agency will agree to hire some 600 more specialists to do the scientific work necessary on new applications for drugs and biological agents. This plan would be phased in over five years, beginning in the 1993 fiscal year.

-Schering-Plough (Madison, NJ) received FDA approval for its recombinant interferon alpha-2b for treatment of chronic hepatitis B, an infectious and sometimes fatal liver disease. The drug is a copy of a naturally occurring protein that acts as an antiviral agent in the body, and is already marketed for treatment of hairy cell leukemia, AIDS-related Kaposi's sarcoma, genital warts, and hepatitis $\mathrm{C}$. Although there are vaccines to prevent hepatitis $B$, this drug is the first treatment for the disease.

-Genzyme (Cambridge, MA) received approval to market Ceredase in Israel. Ceredase is an enzyme replacement therapy for patients with type I Gaucher disease. The drug was approved last year for use in the U.S., and applications are pending in the European Community, Canada, and other countries.

Also, Genzyme is starting phase $\mathrm{I} / \mathrm{II}$ trials for Vianain enzymatic debridement agent. Studies so far have indicated that Vianain appears to be rapid and effective in removing nonviable tissue from burn sites.

Genzyme received orphan drug designation for its cystic fibrosis gene therapy. This is the second orphan drug designa- tion the company has received regarding its research on cystic fibrosis; at the beginning of this year, recombinant cystic fibrosis transmembrane conductance regulator was also named an orphan drug.

-Bio-Technology General (New York) received approval to market its recombinant human growth hormone in Israel for treatment of Turner's syndrome, a genetic disorder in which girls are born with only one healthy $\mathrm{X}$ chromosome.

-Bristol-Myers Squibb (New York) filed a new drug application (NDA) with FDA to market the anti-cancer drug taxol. The company is relinquishing orphan drug designation for taxol, apparently to market the drug as treatment for a wider variety of cancers.

- Cytogen (Princeton, NJ) started phase II trials of its OncoRad ovarian, the company's cancer therapeutic product.

-RML Medical Laboratories (Toronto, Canada) is expanding its phase II trials of Virulizin in the treatment of cancer. The company also plans to pursue regulatory approval to start trials in the U.S. and Europe. Current trials of Virulizin are focused on recurrent and metastatic melanoma, cancer of the pancreas and kidney, and recurrent stomach, rectum, and colon cancer.

- CytRx (Norcross, GA) began a pilot phase II trial with its TherMax gel, a topical therapeutic for pain, inflammation, and healing associated with mild to moderate burns.

-ProCyte (Kirkland, WA) conducted a study in France with peptide copper to halt hair loss in balding men. The study was successful, and the company, as soon as it receives financial backing for the compound, expects to start clinical testing .

-ImClone Systems (New York) is expanding pilot studies of its anti-cancer vaccine, MelVax, for treatment of malignant melanoma. The new patient group will receive MelVax and an adjuvant intended to boost immune response against melanoma tumor cells.

-Somatogen (Boulder, CO) has completed the first stage of phase I trials of its $\mathrm{rHB} 1.1$ recombinant hemoglobin product. The trials were successful. rHB1.l is designed to replace blood lost in surgery.

-Celtrix (Santa Clara, CA) completed phase II trials of its BetaKine for treatment of macular holes, wounds of the retina in the macular region of the eye. Unless successfully repaired, macular holes may diminish visual acuity, leading to legal blindness. The trials had positive results. The company is collecting data in preparation of phase III studies.

-Lynx Therapeutics (Foster City, CA) is preparing an investigational new drug (IND) application for its antisense compound that targets the messenger RNA coded by the p53 gene. The compound will be used to treat myelogenous leukemia, and may later be applied to other types of cancer.

-Immunex (Seattle, WA) started phase I trials of soluble tumor necrosis factor (TNF) receptor for the treatment of sepsis. The initial study will test the ability of soluble TNF receptor to block systemic inflammation caused by bacterial infection.

-Isis Pharmaceuticals (Carlsbad, CA) completed initial phase I trials for its antisense compound Isis 2105 . The compound is designed to treat genital warts caused by the human papilloma virus.

-T Cell Sciences (Cambridge, MA) and SmithKline Beecham (Philadelphia, PA) filed an IND to begin trials of SCR1 for treatment of adult respiratory distress syndrome (ARDS). The initial trials will be conducted in burn patients at risk of developing ARDS; after burn injury, fluid and white blood cells may infiltrate the lungs and lead to pulmonary failure.

-AmylinPharmaceuticals (San Diego, CA) began the first phase of clinical trials to test its synthetic amylin hormone therapy for diabetes. Drugs the company hopes to develop would replace amylin in young diabetics who have difficulties with insulin therapy and where amylin appears to be deficient, and block the action of the hormone in older patients with adult onset diabetes where there is an excess of the 
hormone. Phase I trials are aimed at addressing a treatment for the young.

\section{AIDS CONFERENCE}

-Biocine (Emeryville, CA) reported that 12 vaccinated subjects who received 3 immunizations with the vaccine formula of recombinant gp120 plus adjuvant produced neutralizing antibodies against HIV.

-Genentech's (S. San Francisco, CA) gp120 vaccine was given to $28 \mathrm{HIV}$ negative adult volunteers. Two weeks after the third immunization, 7 of 10 subjects who had been given $300 \mathrm{mcg}$ doses developed fusion inhibition antibody, and neutralization antibody was found in 9 of 10 subjects to the homologous isolate IIIB.

-ImmunoAG's (Wien, Austria) vaccine, recombinantgp 160 , stimulated HIV antibodies and was well tolerated in $60 \mathrm{HIV}$ negativevolunteers.

-Immune Response (San Diego, CA) and Rhone-Poulenc Rorer (Collegeville, PA) presented the results of a doseranging study of their HIV immunotherapeutic. The study demonstrated that the HIV immunotherapeutic significantly stimulated antibody and cellular immune responses in treated patients.

-Tanox Biosystems (Houston, TX), University Hospital of Zürich (Switzerland), and Ciba-Geigy (Basel, Switzerland) completed a study of a monoclonal antibody against HIV. Antibody therapy aims at controlling HIV by providing an infected person with antibodies that can neutralize or block the virus. The results of the limited study seem to show the antibody was well tolerated by the volunteer AIDS patients.

-Genelabs Technologies (Redwood City, CA) presented results of the phase IB study of its anti-AIDS drug, GLQ223, a protein-based pharmaceutical, in patients with AIDS or AIDS related complex. Administration of the drug was safe, and was associated with measurable increases in markers of immulogic activity.

\section{STRATEGIC ALUIANCES}

-Centocor (Malvern, PA) and Xoma (Berkeley, CA) have settled their patent litigation over prospective drugs for the treatment of septic shock. Under the agreement, Centocor will pay royalties to Xoma for any U.S. sales of its monoclonal antibody (MAb) HA-1A. The antibody has yet to be approved by FDA. The companies did not specify how much the royalties would be, but Centocor says they will be less than the 40 percent net Xoma originally asked for. The companies have agreed to forego all future litigation regarding each other's patents and patent applications related to anti-endotoxin MAbs.

Centocor also formed a strategic alliance with Eli Lilly (Indianapolis, IN) that gives Centocor at least $\$ 100$ million and will give Lilly a 5 percent stake in Centocor. Lilly acquires marketing rights to Centocor's HA-1A, as well as an option to spend additional money for rights to Centocor's MAb platelet aggregation inhibitor, CentoRx.

-Immunex and Hoechst (Frankfurt, Germany) agreed to settle all contract and other claims in two lawsuits pending between them. The suits dealt with granulocyte macrophage colony-stimulating factor-a drug Immunex manufactures that is used in autologous bone marrow transplants-and give Immunex exclusive rights to the drug in the U.S., while giving Behringwerke (Marburg, Germany), a subsidiary of Hoechst, significantly increased royalties.

-Pharmaceutical Proteins (Edinburgh, U.K.) and Wyeth-Ayerst (Philadelphia, PA) have entered into a long-term collaboration todevelopspecial use products for metabolic, geriatric, and pediatric applications. The products will utilize the technology of production of proteins in the milk of transgenic animals.

-British Bio-technology (BBT, Oxford, U.K.) and Glaxo (New York) agreed to jointly develop BB-882, BBT's anti-inflammatory drug. The companies will collaborate primarily on the use of the drug in the treatment of asthma. BBT started phase I trials of the drug, and Glaxo is funding the trials. Glaxo will also fund phase II trials.

-Oxford Glycosystems (Abingdon, U.K.) and SmithKline Beecham (Epsom, U.K.) signed a research agreement focused on developing carbohydrate-based inhibitors of selectin-mediated cell adhesion. The goal of the program is to develop therapeutics for treatment of inflammatory diseases.

-Marion Merrell Dow (MMD, Kansas City, MO) will license and continue development of GP-1-468-3, Gensia Pharmaceutical's (San Diego, CA) adenosine regulating agent that is expected to be investigated for treatment of chronic cardiovascular disease.

MMD has also expanded its alliance with Affymax (Amsterdam, the Netherlands). The collaboration was started in 1991, and will now continue until 1997. It covers three specific, but undisclosed, drug discovery targets.

-The Liposome Co. (Princeton, NJ) and Merck (Rahway, $\mathrm{NJ}$ ) have extended their 1991 agreement to formulate and test an antigen associated with Liposome's adjuvant, TLC A-60, to be used as a vaccine against the HIV virus. The antigen is a peptide developed by

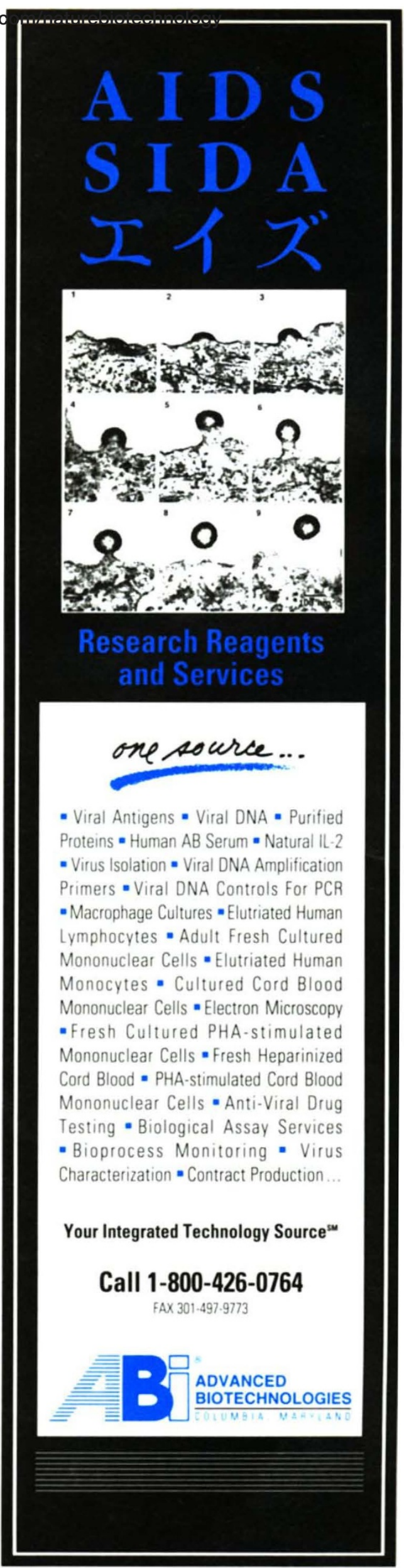

Write in No. 272 on Reader Service Card 
Merck in collaboration with Repligen (Cambridge, MA).

-Genzyme signed a letter of intent to acquire Vivigen (Santa Fe, NM) in a $\$ 40$ million stock swap. Vivigen will be managed as a Genzyme subsidiary by IG Laboratories (Framingham, MA), a majority-owned subsidiary of Genzyme.

-Allelix Biopharmaceuticals (Toronto, Canada) signed an agreement with EuroCetus (Amsterdam, the Netherlands) for EuroCetus to manufacture clinical quantities of recombinant parathyroid hormone ( $\mathrm{rPTH}$ ). Allelix will conduct phase I and phase II trials of rPTH for treatment of acute myocardial infarction.

-Isis Pharmaceuticals signed a threeyear agreement with Kaketsuken (Kumamoto, Japan) and with Mochida Pharmaceutical (Tokyo) to discover and develop antisense oligonucleotides as potential human therapeutic products for the hepatitis $\mathrm{C}$ virus.

-Enzon (S. Plainfield, NJ) and Emisphere (Hawthorne, NY) entered into an agreement directed at developing orally administered pharmaceutical products. The agreement joins two of the companies's technologies: Enzon's pegnology drug-delivery technology, and Emisphere's oral delivery system. The companies's efforts may lead to drugs that last longer in the bloodstream and are protected from gastrointestinal acids.

Enzon also signed an agreement with Cytoclonal Pharmaceutics (Dallas, TX) to jointly develop anticancer drugs. The companies believe they can create new cancer therapies using natural tumorcell killing agents that are targeted to specific tumors.

-Curative Technologies (E. Setauket, NY) acquired the assets of UniqMed, a medical supply distributor of wound care supplies and equipment, and a provider of wound care services.

Curative also signed a definitive agreement with Arbor Health Care (Lima, $\mathrm{OH})$ to provide specialty wound-management services to an inpatient subacute center owned and operated by Arbor. This will be Curative's first venture into patient subacute care.

-Cambridge Biotech (Worcester, MA) will acquire a 15 percent stake in ImmuCell (Portland, ME) through a purchase of common stock. The deal allows Cambridge to acquire a controlling interest over the next two years.

Also, Cambridge formed a joint venture with BioNebraska (Iincoln, NE) and R\&C Enterprises (Omaha, NE) for the development and testing of new therapies for osteoporosis using growth hormone releasing factor to stimulate formation of increased bone mass.

Cambridge reached an agreement in principle with Pasteur Merieux Serums
\&Vaccins (Marnes la Coquette, France) allowing the French company to use Cambridge's Stimulon adjuvant in a new vaccine against influenza. No information regarding the vaccine or the adjuvant was supplied.

-Bio-Technology General (BTG) entered into a distribution agreement with VAW-Flusspat Chemie for BioLon, BTG's hyaluronic-acid-based opthalmic product. VAW, based in Germany, will market the product in Germany though one of its wholly owned subsidiaries, Pharma-Stullin. BioLon is a surgical aid for cataract procedures, intraocular lens implantation, corneal transplantation, and glaucoma filtration.

BTG and SmithKline Beecham ended their licensing agreement that had given SmithKline European marketing rights to BTG's version of human growth hormone.

-Syntro (Kansas City, KS) and Bayer AG (Leverkusen-Bayerwerk, Germany) agreed that Bayer will market and distribute Syntro's PRV/Marker Gold vaccines in Europe. The vaccines prevent pseudorabies, an infectious disease of swine caused by a herpesvirus.

Also, Syntro and Hoechst-Roussel AgriVet (Somerville, NJ) will collaborate on two programs to develop families of vaccines for cattle and horses using Syntro's viral vector technology. Under the agreement, Syntro will develop and manufacture the products, and will receive royalties on sales of the products; Hoechst companies receive exclusive worldwide marketing rights. Viral vector vaccines consist of genetically programmed single viruses that induce immunity against multiple diseases.

-Synbiotics (San Diego, CA) and Rhone Merieux (Lyon, France) reached a cross licensing agreement for specific feline biological products. Specific terms of the agreement were not disclosed.

-Ecogen (Langhorne, PA) and Chevron Chemical reached agreement for the retail distribution of Ecogen's biological pesticide Condor along with Chevron's Ortho brand. Condor is a $B a$ cillus thuringiensis-based bioinsecticide.

- Calgene (Davis, CA) acquired Hodag Chemical (Chicago, IL), which manufactures specialty esters, surfactants, ethoxylates, and other vegetable-oilbased ingredients in the food, cosmetic, soap and detergent, sugar, lubricant, and textile markets. Hodag markets its products nationally and internationally. The merged companies will operate under the Calgene Chemical name.

Also, Calgene will have Meyer Tomatoes (King City, CA), Taylor and Fulton (Palmetto, FL), and Gulfstream Tomato Packers (Perrine, FL) supply its subsidiary, Calgene Fresh, with tomato varieties grown to the company's speci-

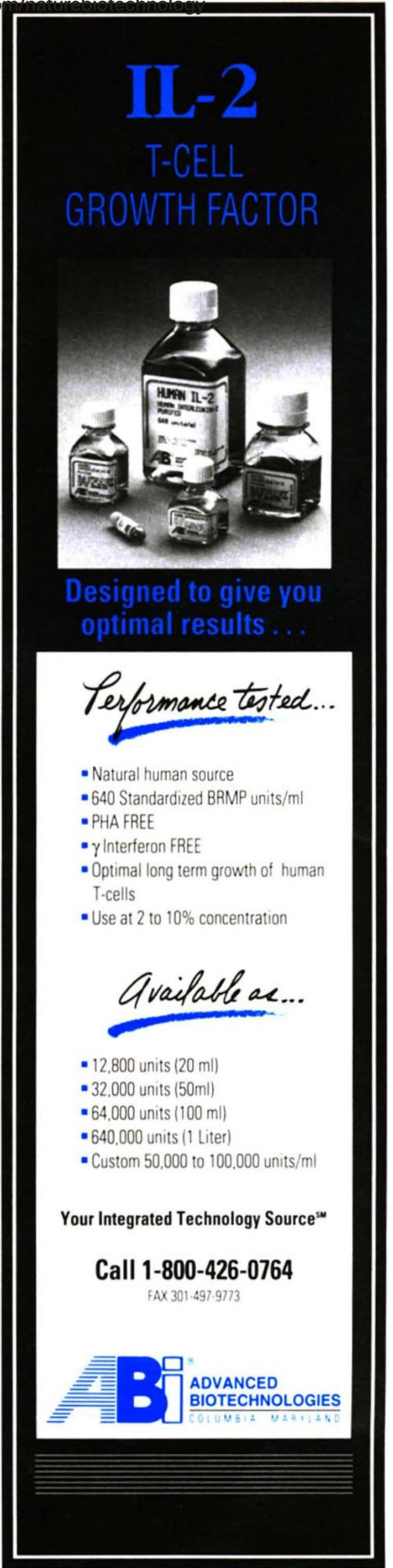

Write in No. 305 on Reader Service Card 
fications for its Flavr-Savr tomato line. -Escagenetics (San Carlos, CA) has expanded its true potato seed (TPS) program to India by signing a producer/ distributor agreement with India-based Kalyani Agro. Field trials with Escagenetics' hybrid TPS and hybrid seed tuber will begin in India in the fall.

\section{FINANCE}

-Several funds managed by U.S.-based Oppenheimer Management invested $\$ 10$ million in Plant Genetic Systems (Ghent, Belgium).

-Xenova (Slough, U.K.) received a second equity investment of $\$ 4.2 \mathrm{mil}$ lion from Genentech. Genentech's total equity investment in Xenova will be $\$ 12$ million under the terms of a drug discovery collaboration expanded last year.

-NPS Pharmaceuticals (Salt Lake City, UT) completed a \$4 million secondround financing with S.R. One (Radnor, PA), a venture capital firm, and Chancellor Capital Management (New York), an institutional investment managementfirm.

-Arcturus Pharmaceutical (Cambridge, MA) completed a $\$ 3.5$ million first-round venture financing. The financing will help the company in its development and commercialization of therapeutic products for dermatological disorders.

-Genzyme is purchasing from Neozyme I, its research spin off, the rights and technology relating to three programs for a total price of $\$ 26 \mathrm{mil}$ lion. The three programs are Thyrogen, a recombinant form of human thyroid stimulating hormone being developed for use as an adjunct in the diagnosis, treatment, and monitoring of thyroid cancer; direct cholesterol testing; and synthetic phospholipids.

-Crop Genetics (Hanover, MD) completed a public offering of 2.5 million shares of stock. The company raised $\$ 9$ million.

-Quadra Logic Technologies (Vancouver, Canada) sold 2.75 million units of stock at a price of $\$ 6.50$ Canadian per unit. The total raised was $\$ 17.9$ million Canadian. The proceeds, plus cash on hand, will be used to fund the costs of clinical drug development, testing, and commercialization of the company's photodynamic therapy products.

- Cantab Pharmaceuticals (Cambridge, U.K.) completed its initial public offering in the U.S. One million shares were sold at a price of $\$ 10$ per share, for a total of $\$ 10$ million. Cantab is the first U.K. biotech company to conduct a public offering exclusively in the U.S.

-Christine Punzo
NEEDTOKNOW ABOUTTHE PAST? BIOTECHNOLOGY

Back copies of

BIO/TECHNOLOGY

are the most efficient, factual way to review past developments of importance in the field.

Every issue provides worldwide coverage of original research, new products and technologies, governmental policies and regulations, patent developments, new strategic partnerships, and more.

You'll also find in-depth reports on market strategies, business opportunities, and project funding.

To get the back copies you need, send your order along with a payment of $\$ 16.50$ per copy ordered to:

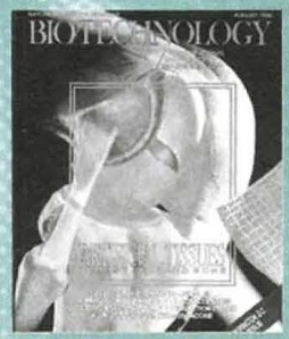

BIO/TECHNOLOGY Back Issues Dept. 65 Bleecker Street New York, NY 10012

For current availability of specific issues:

Phone (212) 477-9600 or Fax (212) 505-1364

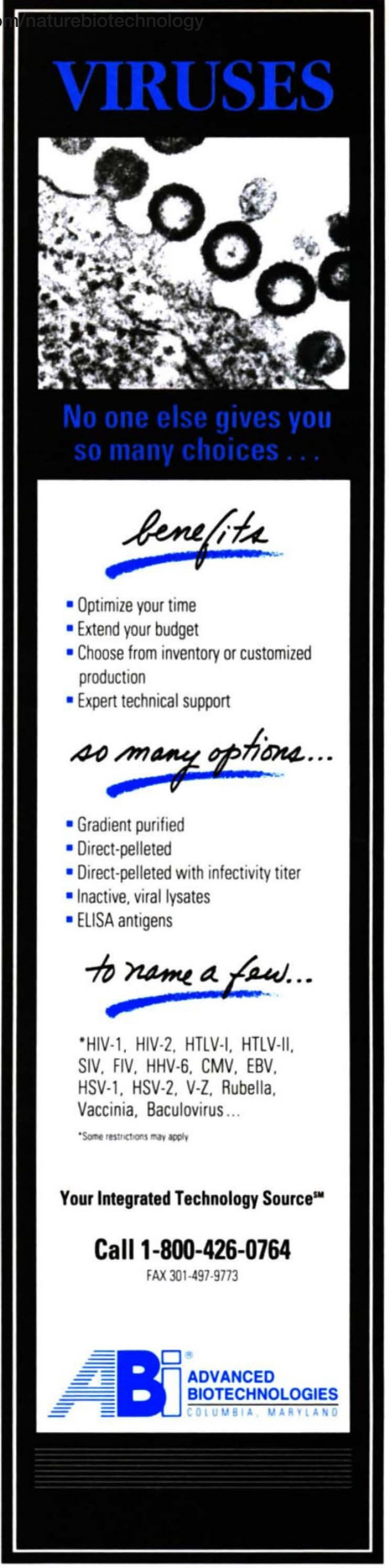

Write in No. 306 on Reader Service Card 